\title{
Seasonality Variability and Periodicities for Ultra-Deep Earthquakes Worldwide
}

\author{
Marilia Hagen ${ }^{1}$, Anibal Azevedo² \\ ${ }^{1}$ Retired, Universidade Federal Fluminense, Instituto de Fisica, Niteroi, Brazil \\ ${ }^{2}$ Faculdade de Ciências Aplicadas da Unicamp, São Paulo, Brazil \\ Email: marhagen@indiana.edu, anibal.azevedo@fca.unicamp.br
}

How to cite this paper: Hagen, M. and Azevedo, A. (2019) Seasonality Variability and Periodicities for Ultra-Deep Earthquakes Worldwide. Open Journal of Earthquake Research, 8, 1-18.

https://doi.org/10.4236/ojer.2019.81001

Received: November 29, 2018

Accepted: December 25, 2018

Published: December 28, 2018

Copyright ( 92019 by authors and Scientific Research Publishing Inc. This work is licensed under the Creative Commons Attribution International License (CC BY 4.0).

http://creativecommons.org/licenses/by/4.0/

(c) (i) Open Access

\begin{abstract}
Our last study found that deepest-depth earthquakes with larger magnitudes (M6 or above) showed seasonality, which is dependent on the area searched. The main results indicated strong evidence that the causes for the delays in enhancements along the period investigated were due to the tectonics also, not only the season. Therefore, if the inquiry was about an area in Northern Hemisphere, the season in which the increases occurred is different than the season in the Southern Hemisphere. Also, higher latitudes in the Northern Hemisphere or around the Equator, displayed seasonality similarly where the tremors appear to increase during the Spring and Summer. This did not happen to the Southern Hemisphere where disturbances and anomalies occurred without showing much connection to the seasons in the analyzed period. However, some of the regions presented periodicities independent from the seasons.
\end{abstract}

\section{Keywords}

Seasons, Subduction Zones, Earthquakes, Periodicity, South Hemisphere

\section{Introduction}

In the first study [1], we examined deep and ultra-deep earthquakes (DQ and UDQ) worldwide, during the period 1996-2017. This study showed that UDQ in South America happened within the continent instead of the ocean, as often happens in other areas. It is notable that these DQ and UDQ were disturbed with periods of intense enhancements during some of the years observed. It could be attributed to the seasons, or not, and is the focus of our next investigations. The second paper [2] analyzed the period 1999-2017 while considering four different locations and only UDQs. The outcomes identified a slight rise 
during Spring or Fall. Philippines enhancements only occur during the Summer. The Southern Hemisphere exhibited increases also during the Spring and Fall; however, South America did not display a reliable variability. Our conclusions were that it is necessary to isolate more regions with deepest depths occurrences during a larger period to have a better idea of the history.

We also decided to verify a former paper [3] to confirm if only greater magnitudes show seasonality in those subduction zones. The last study [4] followed the initial conditions of five different areas, two in the Northern Hemisphere, and three in the Southern Hemisphere, earthquakes of magnitude $M \geq 6$, and at depths of $\geq 500 \mathrm{~km}$. It is of paramount importance to isolate these depths to understand if the disturbances are due by seasons or if any other parameter could relate to variations within the Earth. Evidence was found for earthquakes in the Northern Hemisphere occurring in the Summer and in the Southern Hemisphere they happened in the Spring. Nevertheless, these results are specific and could not be generalized, for example, with magnitudes $M \geq 2.5$. Therefore, the last step is considered in this paper and will take all the possible magnitudes in the deepest depths to check if it would change the formerly completed evaluation. The initial conditions will be depths of $\geq 500 \mathrm{~km}$, the same five locations formerly studied, magnitudes of $M \geq 2.5$, during the period 1987-2017, which is a reasonable historic range for these events. The magnitude parameter starting at the lower values will allow for a better possibility of determining any connection between the subduction zones considered and the seasons.

The results around the Circum Pacific area showed that Northern Hemisphere regions had similar reactions for the seasons, as expected. The Southern Hemisphere also had feedback, but the enhancements dependencies appeared to be beyond the seasons.

The next sections will describe our statistical, mathematical model and how it is used to find the relationship between seasons and enhancement of events in the five chosen areas.

\section{Method Used}

Our method to determine if earthquakes increase, decrease, or remain constant in each region and depth begins with defining the regions with occurrences of earthquakes at depths of $\geq 500 \mathrm{~km}$. There are five areas chosen: North Pacific (Japan, Russia), Philippines (including part of Northern Mariana Islands), South Pacific (essentially the area around Indonesia), South America, and Fiji surrounds (including the Vanuatu region). The period analyzed is 1987-2017 or 30 years. We used the magnitudes of $M \geq 2.5$, which is the minimum value of our working catalogs [5] [6].

In this paper, the extended periods are statistically productive and point to better results. We constructed tables of $\mathrm{N}$ values for each year searched and determined the average number of events per year by dividing the sum of all recorded events by 30 . 


\subsection{Construction of Plots and Tables}

The dataset is comprised of earthquakes recorded during the period mentioned. The sum of data values was $\mathrm{y}_{1}=$ data recorded in the chosen year level $\mathrm{D} \geq 500$ $\mathrm{km}$ for the depths in the region $\mathrm{X}(\mathrm{A}, \mathrm{B}, \mathrm{C}, \mathrm{D}, \mathrm{E})$

$$
\sum_{n 0}^{n n} Y_{n}=y_{n 0}+y_{n 1}+\cdots+y_{n n}
$$

where $n=1987, \cdots, 2017$, and range n' is 30 years.

The mean is defined as

$$
\begin{gathered}
\text { Mean }=M=\frac{\sum_{n 0}^{n n} Y_{n}}{30} \\
\text { Data value }- \text { mean }=Y_{n}^{\prime}
\end{gathered}
$$

If $Y_{n}^{\prime}>M$, the value is higher than one during that year and it means the number of earthquakes exceeds the average. On the other hand, if $Y_{n}^{\prime}<M$, the number will be less than one during that year, indicating that the number of earthquakes was below the average. It is also possible to have a result of zero (was not common, most of the dataset), which would mean there was no available data.

\subsection{Coordinates and Seasons for the Regions Examined}

Calculating variance from annual averages will help to define and explain the locations where ultra-deep earthquakes (UDQ) occur. Table 1 lists the boundary coordinates of each region studied. Our new step for UDQ is to consider the following parameters: depths of $\geq 500 \mathrm{~km}$, magnitudes $M \geq 2.5$, and subduction locations defined by coordinates. Two of these locations are in the Northern Hemisphere, and the three others are in the Southern Hemisphere. They are North Pacific and Philippines for the Northern Hemisphere, South Pacific (Indonesia), South America, and Fiji for the Southern Hemisphere.

The coordinates to construct our mathematical models are displayed in Table 1.

The coordinates make a subdivision of areas where UDQ happen. Although it is clearly defined at the Northern and Southern Hemisphere, it is not possible to comprise all the locations with deepest earthquakes within these coordinates. Regardless, the five places give a fair idea of a possible seasonality.

Table 2 establishes the seasons worldwide.

Table 1. Locations and coordinates for earthquakes calculated.

\begin{tabular}{cc}
\hline North Hemisphere & Coordinates \\
\hline North Pacific & $67.067 \mathrm{~N}, 30.449 \mathrm{~S},-144.844 \mathrm{E},-226.934 \mathrm{~W}$ \\
Philippines, Mariana's & $20.633 \mathrm{~N}, 1.862 \mathrm{~S},-223.94 \mathrm{E},-252.246 \mathrm{~W}$ \\
South Hemisphere & $10.207 \mathrm{~N},-16.236 \mathrm{~S},-184.922 \mathrm{E},-263.672 \mathrm{~W}$ \\
South Pacific & $5.545 \mathrm{~N},-53.54 \mathrm{~S},-65.215 \mathrm{E},-87.539 \mathrm{~W}$ \\
South America & $-9.243 \mathrm{~N},-35.29 \mathrm{~S},-197.227 \mathrm{~W},-119.18 \mathrm{E}$ \\
Fiji &
\end{tabular}


Table 2. Seasons for northern and southern hemisphere.

\begin{tabular}{cccc}
\hline North Hemisphere & Range & South Hemisphere & Range \\
\hline Spring & March 1- May 31 & Spring & Sept 1-Nov 30 \\
Summer & Jun 1- Aug 31 & Summer & Dec 1-Feb 28 \\
Fall & Sept 1- Nov 30 & Fall & March 1-May 30 \\
Winter & Dec 1- Feb 28 & Winter & Jun 1-Aug 31 \\
\hline
\end{tabular}

With Table 1 and Table 2, is constructed the mathematical model for the five different regions by season. The data are from catalogs [5] and [6] for thirty years. Now it is possible to work with our mathematical model to construct tables for each region, studied around the circum Pacific, following the requests as $M \geq 2.5$, depths of $\geq 500 \mathrm{~km}$, and the recorded variations of earthquakes in each location defined in Table 1. It is important to remind ourselves that we are searching for data varying monthly during the period. Reliability in statistical studies is based on the history of data, but also depending on how precise the data in the records is. Next, we divided the data into two parts, two areas located at the Northern Hemisphere, and the three others in the Southern Hemisphere.

\section{Results for Northern Hemisphere}

\subsection{North Pacific Variations Monthly and Seasonal}

The next Table 3 and Table 4, are the results at the North Pacific area. Table 3 is constructed with the data from the catalog [5].

Using Table 3, we constructed Figure 1, which shows the monthly development of earthquakes. From the figure, we can notice the enhancement of events happened in May (end of Spring), July, and August (Summer), meaning 33\% of the performance in the area. Table 4 and Figure 2 are constructed by dividing the past results into the four seasons. We collected the highest monthly average for each season, as displayed in Table 4, to build Figure 2. Figure 2 demonstrates May (Spring) and July (Summer) with $60 \%$ of events. Therefore, the outcome at the North Pacific shows most of the enhancement of earthquakes start at the end of Spring, covering the Summer, and are fewer in the Winter and Fall.

\subsection{Philippines Variations Monthly and Seasonal}

The next two tables, Table 5 and Table 6, refer to the Philippines. The first table refers to the average data as the former one, listed monthly. The second table represents the Philippines' seasons.

Table 5 created a percentage plot of monthly variations in the Philippines. Using Figure 3, we observe that during May (Spring) and July (Summer) in this region the number of events activities is enhanced by $24 \%$ while other months had smoother occurrences below 10\%. Therefore, the enhancement of earthquakes happens to the same seasons as in the North Pacific.

The next table, Table 6, presented Summer in the Philippines as responsible 
Table 3. Average earthquake numbers monthly for 30 years (1987-2017). The number is positive or zero. Zero means no event recorded, one expects the occurrences were average, above one indicates an enhancement of earthquakes detected in the North Pacific. Maximum anomalies occurred in July/August 1995.

\begin{tabular}{|c|c|c|c|c|c|c|c|c|c|c|c|c|}
\hline Year & January & February & March & April & May & June & July & August & September & October & November & December \\
\hline 1987 & 0.3 & 1.3 & 0.7 & 0.7 & 1.2 & 0.3 & 0.8 & 0.2 & 0 & 0.8 & 0.3 & 0.5 \\
\hline 1988 & 0 & 0 & 0.3 & 0 & 0.5 & 0.3 & 0.5 & 0.5 & 0.5 & 0 & 0.3 & 0 \\
\hline 1989 & 0.7 & 0 & 0 & 0.3 & 0.5 & 0 & 0.8 & 0.2 & 1 & 0 & 0 & 0.5 \\
\hline 1990 & 1 & 0.7 & 0.3 & 1 & 0.5 & 0 & 0.2 & 0.8 & 1.5 & 0.8 & 0.8 & 1 \\
\hline 1991 & 0.3 & 0 & 0 & 0.7 & 0.8 & 0 & 1.2 & 0.8 & 0.5 & 0 & 0.3 & 0.5 \\
\hline 1992 & 2.3 & 0.3 & 0.7 & 0.7 & 1 & 1 & 1 & 0.5 & 0 & 0.3 & 1 & 0 \\
\hline 1993 & 1 & 0.3 & 0.7 & 0.3 & 0.5 & 0.7 & 0 & 0.5 & 0.5 & 0.8 & 1.3 & 0.5 \\
\hline 1994 & 1 & 0.7 & 0.3 & 0.3 & 0 & 0 & 0.2 & 0.2 & 1 & 0.3 & 0.3 & 0.5 \\
\hline 1995 & 0.7 & 1.3 & 0 & 1.3 & 0 & 0.7 & 4.5 & 4.5 & 1 & 2 & 1 & 1.5 \\
\hline 1996 & 0.7 & 0.7 & 2.3 & 0 & 1 & 2 & 1 & 1 & 1.5 & 1 & 0.3 & 2.5 \\
\hline 1997 & 1.3 & 0 & 0.7 & 1.3 & 1.5 & 0.7 & 1 & 1 & 0.5 & 1 & 0.8 & 4 \\
\hline 1998 & 1.3 & 4 & 1.3 & 2.3 & 0.8 & 2 & 0.8 & 0.8 & 2.5 & 0.3 & 1 & 0 \\
\hline 1999 & 1 & 0.7 & 2 & 2 & 0.2 & 0.7 & 0.8 & 0.8 & 1.5 & 1.3 & 1 & 0.5 \\
\hline 2000 & 1 & 1 & 1.3 & 0 & 0.8 & 1 & 0.2 & 0.2 & 1 & 0.3 & 0.3 & 1.5 \\
\hline 2001 & 0.3 & 1 & 0 & 1 & 1.5 & 1 & 1 & 1 & 1.5 & 1 & 0 & 1 \\
\hline 2002 & 1.7 & 1.3 & 1 & 0 & 3 & 1 & 1.5 & 1.5 & 2 & 0.3 & 2 & 2 \\
\hline 2003 & 1.3 & 0.7 & 1.7 & 1.3 & 2 & 1.6 & 1.3 & 1.3 & 5 & 1.7 & 2 & 1.5 \\
\hline 2004 & 0.3 & 1.3 & 1.7 & 2 & 0.8 & 1.6 & 1.5 & 1.5 & 2 & 2 & 1.3 & 1.5 \\
\hline 2005 & 0.3 & 3.3 & 1 & 1 & 1 & 1.6 & 1.5 & 1.5 & 2 & 3 & 1.6 & 1 \\
\hline 2006 & 1.3 & 0.7 & 0.3 & 0.3 & 1.4 & 1.6 & 1.3 & 1.3 & 1.5 & 2 & 3.6 & 1.5 \\
\hline 2007 & 2 & 1.3 & 1.7 & 0.7 & 2.5 & 1.6 & 1 & 1 & 1.5 & 2 & 2 & 2.5 \\
\hline 2008 & 1.7 & 0.7 & 0.7 & 2.3 & 0.2 & 1.6 & 1 & 1 & 2.5 & 2 & 1 & 2.5 \\
\hline 2009 & 1.3 & 0 & 1 & 0.7 & 0 & 0 & 0.5 & 0.5 & 0 & 2.3 & 0.3 & 0.5 \\
\hline 2010 & 0 & 1 & 0.3 & 0 & 0.8 & 0 & 1.5 & 1.5 & 0.5 & 1.3 & 0.3 & 0.5 \\
\hline 2011 & 0.3 & 0.7 & 1.7 & 0.3 & 0.2 & 0.3 & 0.2 & 2 & 0 & 1.3 & 0.6 & 1.5 \\
\hline 2012 & 0.3 & 1 & 0 & 0.7 & 0.2 & 1.6 & 0.8 & 1 & 0 & 0.7 & 0.3 & 0 \\
\hline 2013 & 0 & 0 & 0 & 1.3 & 3 & 1.6 & 0.2 & 0.5 & 1.5 & 2.3 & 1 & 2.5 \\
\hline 2014 & 1.7 & 1 & 1.7 & 2 & 2 & 1.3 & 1 & 1.5 & 1.5 & 1.3 & 0.6 & 2 \\
\hline 2015 & 0.7 & 1.7 & 1.3 & 0.7 & 1.5 & 1 & 0.8 & 0.8 & 1.5 & 1.3 & 1.6 & 2.5 \\
\hline 2016 & 1.7 & 0.7 & 0.7 & 1.3 & 1.2 & 0.7 & 0.5 & 0.5 & 2.5 & 1 & 1.3 & 0.5 \\
\hline 2017 & 1.7 & 0.7 & 1.7 & 1.3 & 1.2 & 1.6 & 1.1 & 1.3 & 2 & 1.7 & 1 & 1.5 \\
\hline
\end{tabular}

Table 4. North Pacific seasonality showing the months with the highest variation during the entire year.

\begin{tabular}{cc}
\hline \multicolumn{1}{c}{ North Pacific seasons } \\
\hline Months & Averages \\
\hline January (Winter) & 3 \\
May (Spring) & 5 \\
July (Summer) & 4 \\
October (Fall) & 3 \\
\hline
\end{tabular}




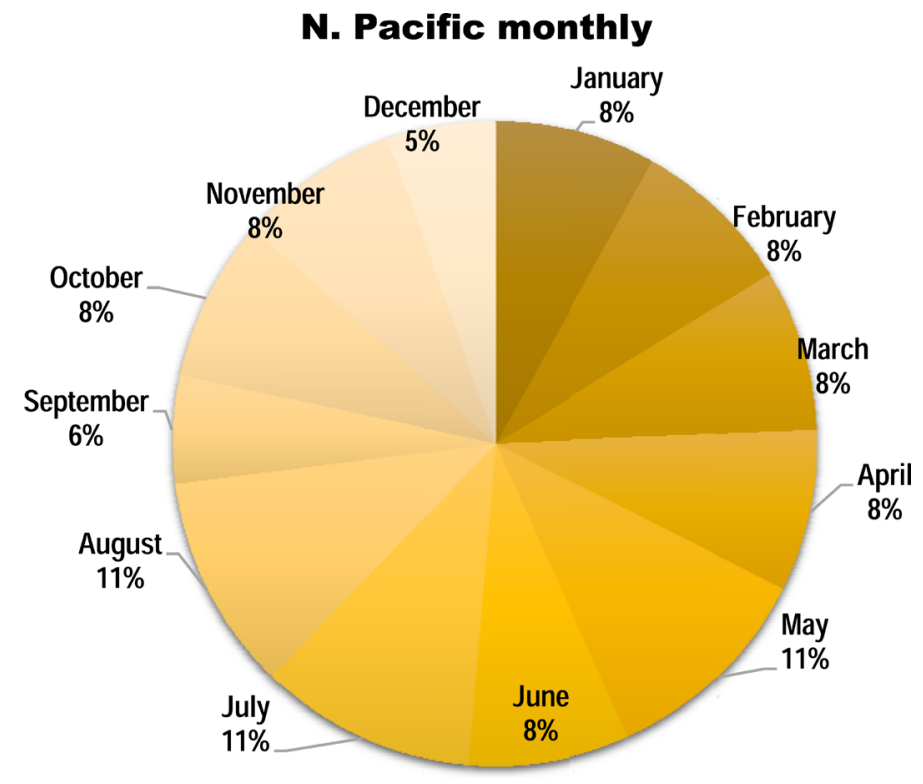

Figure 1. The earthquake activity since $M \geq 2.5$, at the North Pacific, which includes Russia, Sea of Okhotsk, and Japan, period 1987-2017, by month.

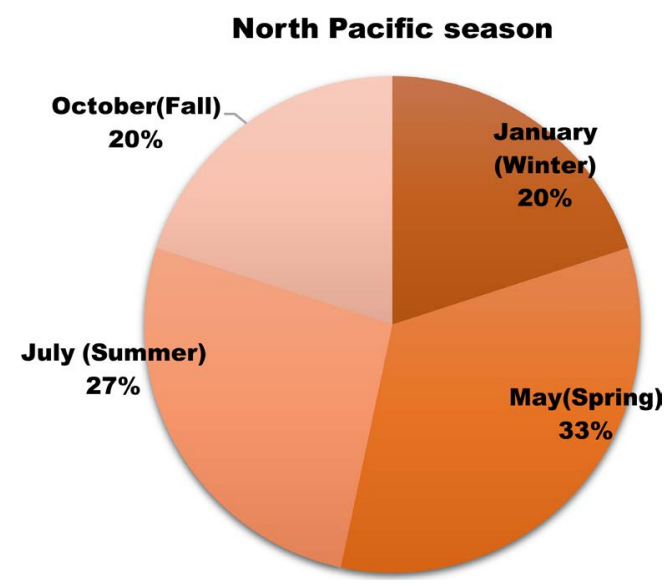

Figure 2. North Pacific seasonality, period 1987-2017, $\mathrm{M} \geq 2.5$, it included the same countries and regions as Figure 1.

for the $31 \%$ of total activity for the year, followed closely by Spring. Table 6 is plotted in Figure 4.

Figure 4 shows that May (Spring) and July (Summer) are responsible for 56\% of the earthquake events per year; therefore, we conclude that the area at the North Circum Pacific presented the highest seasonality enhancement during the Spring and Summer.

Next, we analyze the Southern Hemisphere and some of the chosen regions, such as those identified in Table 2 .

\section{Results Southern Hemisphere}

\subsection{South Pacific (Indonesia) Region}

Table 7 shows the monthly average distribution of earthquakes within the initial 
Table 5. Average earthquake numbers monthly for 30 years (1987-2017). The number is all positive or zero. Zero means no event recorded, one expects the occurrences were average, above one indicates an enhancement of earthquakes detected, in the Philippines. No anomalies were found. The Philippines had zero spots in higher number compared with North Pacific.

\begin{tabular}{|c|c|c|c|c|c|c|c|c|c|c|c|c|}
\hline Year & January & February & March & April & May & June & July & August & September & October & November & December \\
\hline 1987 & 0.5 & 2 & 0.5 & 0.5 & 2 & 0.5 & 0.5 & 0 & 0 & 0.5 & 0 & 0.5 \\
\hline 1988 & 0 & 0 & 0.5 & 0 & 0 & 0 & 0 & 0.5 & 0 & 0 & 0 & 0 \\
\hline 1989 & 0.5 & 0 & 0 & 0 & 0.5 & 0 & 0.5 & 0 & 0.5 & 0 & 0 & 0.5 \\
\hline 1990 & 0.5 & 0.5 & 0.5 & 0 & 0 & 0 & 0 & 1 & 0 & 0.5 & 0 & 0 \\
\hline 1991 & 0 & 0 & 0 & 0.5 & 1 & 1 & 0 & 0 & 0 & 0 & 0.5 & 0.5 \\
\hline 1992 & 3 & 0 & 1 & 0.5 & 0 & 0 & 1 & 0.5 & 0 & 0.5 & 1 & 0 \\
\hline 1993 & 1 & 0.5 & 0 & 0 & 1 & 0 & 0 & 0.5 & 0.5 & 0.5 & 0.5 & 0 \\
\hline 1994 & 0 & 0 & 0 & 0 & 0 & 0 & 0.5 & 0 & 0 & 0.5 & 0 & 0 \\
\hline 1995 & 0 & 0.5 & 0 & 0.5 & 0 & 0 & 1 & 0.5 & 0 & 0.5 & 1 & 0.5 \\
\hline 1996 & 0.5 & 1 & 1 & 0.5 & 1 & 3 & 0 & 0.5 & 0.5 & 1 & 0.5 & 1 \\
\hline 1997 & 0 & 0 & 2 & 0.5 & 2 & 0.5 & 0 & 1 & 1 & 1 & 0 & 3 \\
\hline 1998 & 1 & 1 & 0 & 2 & 1 & 2 & 0.5 & 0 & 2 & 0 & 0.5 & 0 \\
\hline 1999 & 0 & 1 & 0.5 & 0.5 & 0 & 1 & 0 & 0 & 0 & 2 & 2 & 0.5 \\
\hline 2000 & 0.5 & 0 & 2 & 0 & 0.5 & 0.5 & 2 & 0.5 & 0 & 0 & 0.5 & 0 \\
\hline 2001 & 0 & 1 & 1 & 2 & 1 & 0.5 & 0 & 0 & 0.5 & 0.5 & 0 & 0 \\
\hline 2002 & 2 & 0 & 1 & 0 & 0 & 1 & 0.5 & 0.5 & 2 & 0.5 & 1 & 0.5 \\
\hline 2003 & 1 & 0 & 0 & 2 & 3 & 0 & 0.5 & 1 & 0 & 1 & 2 & 0.5 \\
\hline 2004 & 0 & 2 & 1 & 1 & 1 & 2 & 1 & 0.5 & 1 & 0 & 1 & 0.5 \\
\hline 2005 & 0.5 & 3 & 0.5 & 1 & 0.5 & 1 & 0.5 & 3 & 0.5 & 0.5 & 2 & 0 \\
\hline 2006 & 2 & 1 & 0 & 0 & 1 & 2 & 3 & 2 & 1 & 3 & 4 & 2 \\
\hline 2007 & 2 & 0.5 & 1 & 0 & 0.5 & 0.5 & 1 & 0.5 & 1 & 0 & 2 & 0 \\
\hline 2008 & 2 & 0.5 & 0.5 & 1 & 1 & 1 & 1 & 0.5 & 2 & 0.5 & 0.5 & 2 \\
\hline 2009 & 2 & 0 & 1 & 0 & 0.5 & 0.5 & 0.5 & 0 & 0 & 4 & 0 & 0 \\
\hline 2010 & 0 & 0.5 & 0.5 & 0 & 0 & 0 & 10 & 3 & 0 & 1 & 0.5 & 0.5 \\
\hline 2011 & 1 & 2 & 0 & 0 & 1 & 0.5 & 0.5 & 0.5 & 0 & 1 & 1 & 1 \\
\hline 2012 & 0.5 & 0.5 & 0 & 1 & 0.5 & 2 & & 0.5 & 0 & 0.5 & 1 & 0 \\
\hline 2013 & 0 & 0 & 0 & 0.5 & 0 & 0 & 0.5 & 1 & 0.5 & 2 & 0.5 & 1 \\
\hline 2014 & 1 & 1 & 2 & 2 & 1 & 0 & 0.5 & 2 & 1 & 1 & 0.5 & 1 \\
\hline 2015 & 0.5 & 0.5 & 1 & 1 & 1 & 0.5 & 0.5 & 0.5 & 0.5 & 0.5 & 2 & 2 \\
\hline 2016 & 2 & 0.5 & 0.5 & 2 & 1 & 1 & 0.5 & 0.5 & 0 & 0.5 & 2 & 0.5 \\
\hline 2017 & 2 & 0.5 & 0.5 & 1 & 0.5 & 0 & 1 & 2 & 0 & 1 & 1 & 1 \\
\hline
\end{tabular}

Table 6. Philippines maximum by season.

\begin{tabular}{cc}
\hline Philippines seasons & average \\
\hline January (Winter) & 2 \\
May (Spring) & 3 \\
July (Summer) & 3 \\
November(Fall) & 2 \\
\hline
\end{tabular}




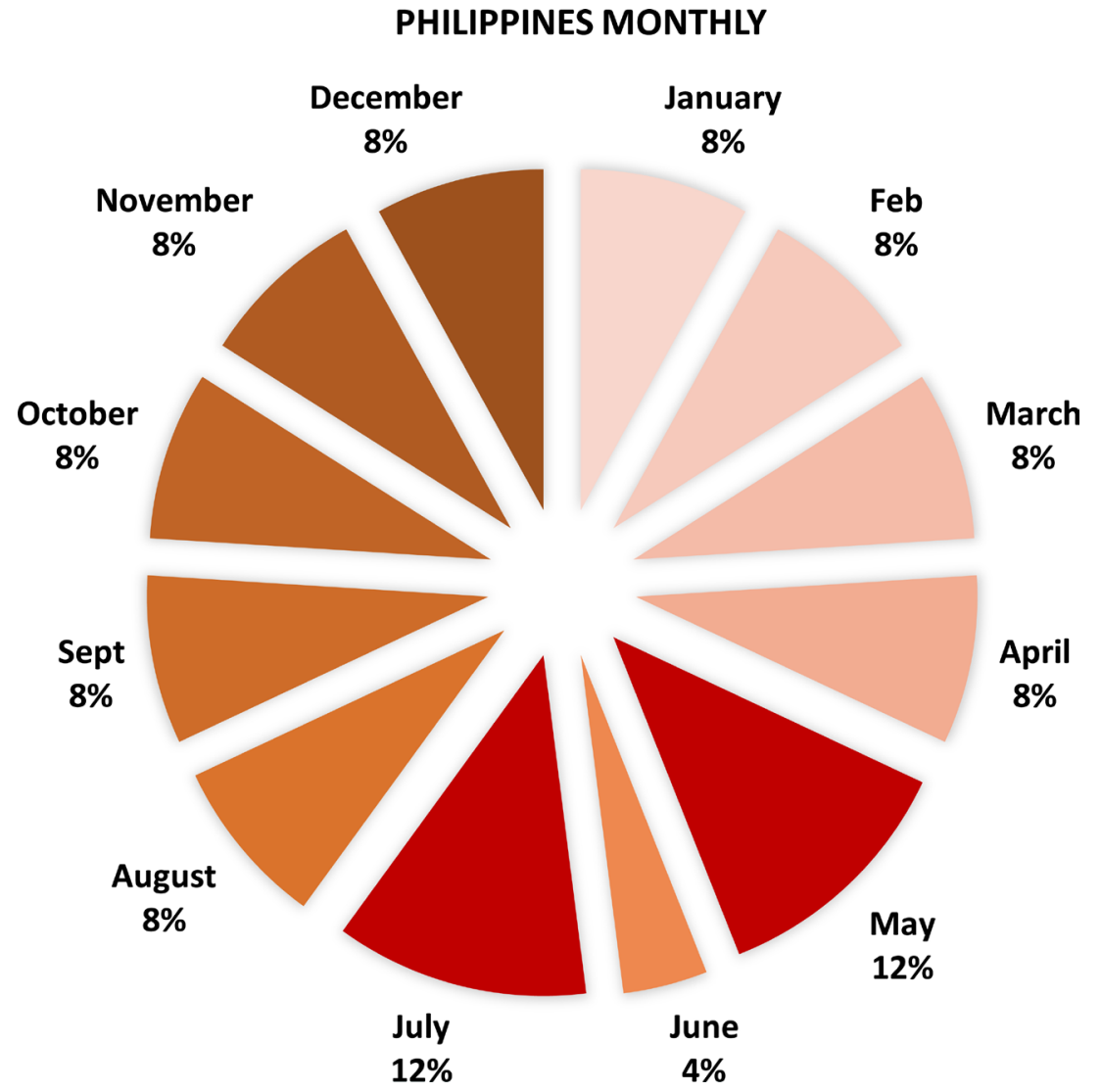

Figure 3. The monthly distribution in the second area in the Northern Hemisphere, Philippines, same initial conditions as the North Pacific. Results are quite different.

\section{Philippines seasons}

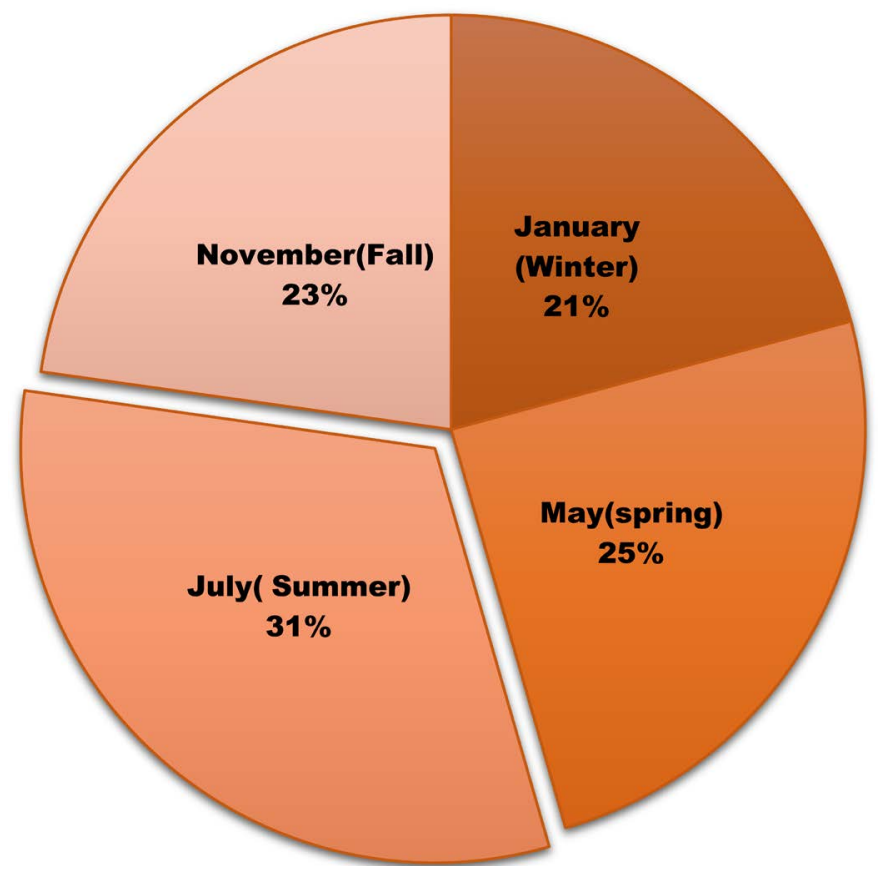

Figure 4. The Philippines has a different enhancement during the Summer, where July is the month with more occurrences. 
Table 7. The average of earthquakes in Indonesia is calculated by month; zero means during that month and year no events were recorded (it is more frequent than in Northern). The number one means there was on average amount, and only those values above 1.5 are considered an enhancement. There were also anomalies in several years; the biggest occurred in 1996, with nine times the average in July.

\begin{tabular}{|c|c|c|c|c|c|c|c|c|c|c|c|c|}
\hline Year & January & February & March & April & May & June & July & August & September & October & November & December \\
\hline 1987 & 1 & 3 & 0.5 & 1 & 0 & 0 & 0 & 1 & 1 & 0.5 & 3 & 0.5 \\
\hline 1988 & 0 & 0 & 1.5 & 0 & 1 & 1 & 0 & 0 & 0 & 1 & 0 & 2.5 \\
\hline 1989 & 0 & 1 & 0.5 & 1 & 0 & 0 & 0.5 & 1 & 0.5 & 0 & 0 & 0.5 \\
\hline 1990 & 1 & 0 & 0 & 0 & 1 & 1 & 3 & 2 & 1 & 0.5 & 1 & 0 \\
\hline 1991 & 0 & 0 & 0 & 0 & 0 & 1 & 0.5 & 1 & 1 & 0 & 0 & 1.5 \\
\hline 1992 & 0 & 0 & 1 & 1 & 0 & 2 & 0 & 1 & 0 & 0.5 & 1 & 0.5 \\
\hline 1993 & 0 & 0 & 0.5 & 0 & 0 & 0 & 0.5 & 1 & 0.5 & 0 & 1 & 0 \\
\hline 1994 & 0 & 0 & 0.5 & 2 & 0.5 & 0 & 0 & 3 & 1 & 0.5 & 1 & 0 \\
\hline 1995 & 0 & 0 & 0 & 0 & 1.5 & 1 & 0.5 & 1 & 0 & 1.5 & 0 & 1.5 \\
\hline 1996 & 3 & 1 & 0.5 & 0 & 0.5 & 1 & 9 & 3 & 0 & 2 & 1 & 0.5 \\
\hline 1997 & 5 & 1 & 1.5 & 0 & 0.5 & 1 & 2 & 1 & 0.5 & 0 & 0 & 0.5 \\
\hline 1998 & 1 & 1 & 0 & 1 & 1.5 & 2 & 0 & 0 & 0 & 1 & 1 & 1 \\
\hline 1999 & 0 & 3 & 0.5 & 0 & 0 & 0 & 0 & 0 & 0 & 2.5 & 0 & 0 \\
\hline 2000 & 1 & 1 & 0 & 3 & 0.5 & 1 & 1 & 4 & 2 & 0.5 & 1 & 0.5 \\
\hline 2001 & 0 & 3 & 0.5 & 1 & 0.5 & 0 & 1.5 & 0 & 1 & 0 & 1 & 0.5 \\
\hline 2002 & 0 & 2 & 0.5 & 0 & 0.5 & 2 & 1 & 2 & 0 & 1.5 & 2 & 1.5 \\
\hline 2003 & 1 & 1 & 0.5 & 1 & 3 & 3 & 0.5 & 2 & 1 & 1 & 0 & 0 \\
\hline 2004 & 6 & 0 & 1 & 3 & 2 & 7 & 2 & 2 & 3 & 1 & 2 & 0 \\
\hline 2005 & 1 & 1 & 1 & 3 & 1 & 2 & 2.5 & 1 & 1 & 0.5 & 1 & 1.5 \\
\hline 2006 & 1 & 3 & 2.5 & 1 & 0.5 & 2 & 0.5 & 0 & 1 & 1 & 3 & 1 \\
\hline 2007 & 1 & 2 & 1.5 & 3 & 1.5 & 4 & 2.5 & 1 & 1 & 0.5 & 1 & 1.5 \\
\hline 2008 & 1 & 1 & 1 & 1 & 0.5 & 0 & 1.5 & 2 & 0.5 & 1.5 & 1 & 4 \\
\hline 2009 & 1 & 1 & 0.5 & 2 & 0.5 & 1 & 0 & 0 & 0.5 & 1 & 0 & 0.5 \\
\hline 2010 & 3 & 0 & 0.5 & 0 & 0.5 & 0 & 0 & 1 & 0.5 & 0.5 & 0 & 0.5 \\
\hline 2011 & 1 & 0 & 1 & 0 & 0.5 & 0 & 0 & 2 & 0.5 & 0 & 2 & 0.5 \\
\hline 2012 & 1 & 0 & 2 & 1 & 0.5 & 0 & 0 & 1 & 0.5 & 0.5 & 0 & 1 \\
\hline 2013 & 1 & 1 & 0.5 & 0 & 0.5 & 0 & 0.5 & 2 & 1 & 2 & 2 & 0.5 \\
\hline 2014 & 3 & 2 & 0.5 & 1 & 1 & 1 & 0.5 & 3 & 2 & 2 & 3 & 1.5 \\
\hline 2015 & 1 & 7 & 1.5 & 1 & 1 & 0 & 1.5 & 3 & 0.5 & 2 & 0 & 1.5 \\
\hline 2016 & 3 & 2 & 2.5 & 1 & 2 & 3 & 0 & 2 & 1 & 1 & 2 & 2 \\
\hline 2017 & 2 & 3 & 1 & 1 & 1 & 1 & 0.5 & 3 & 2.5 & 1.5 & 1 & 1 \\
\hline
\end{tabular}

conditions formerly defined. South Hemisphere, presented months with a lack of earthquakes as indicated with zero, in higher number than Northern, within the average indicated as one, and enhancement months, when only the values above 1.5 were considered for results. We found anomalies higher than those at the North Hemisphere, which means several years presented one or two months 
with common occurrences above than normal. In Indonesia, it was highest in 1996 (July), in 2004 (January and June), and in 2015 (February). Those anomalies are not involved in our calculations as particularly crucial for the seasonality of the location and had little influence on the estimates.

Consulting Table 7, only in 1996 were July events were followed with an increase in August. It is interesting that in Indonesia six months have an increase in earthquakes independent of the season. These months were March, May (Fall), July (Winter), September, October (Spring) and December (Summer), as we see in Figure 5.

Thus, South Pacific (Indonesia area) results showed that UDQ independent of the magnitude value did not display seasonality such as that seen in the North Hemisphere. Table 8 and Figure 6 also presented a smoother difference between seasons although Winter has a percentage just $1 \%$ higher than the other seasons. This could be easily explained by the anomalies observed during the three months of the Winter (June through August), in several years examined.

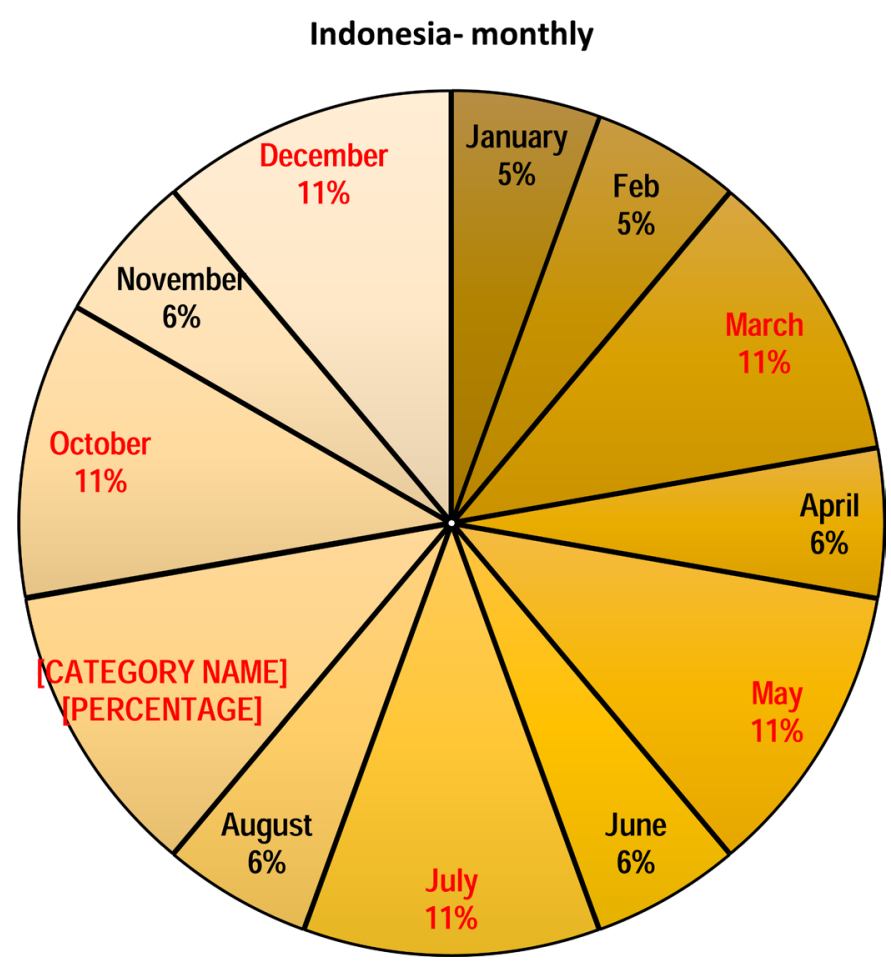

Figure 5. South Hemisphere region, Indonesia displays months with higher earthquake increases along the year.

Table 8. Indonesia season showing the highest averages distribution by month.

\begin{tabular}{cc}
\hline Indonesia season & average \\
\hline March (Fall) & 1.7 \\
July (Winter) & 1.9 \\
October (Spring) & 1.8 \\
December (Summer) & 1.8 \\
\hline
\end{tabular}




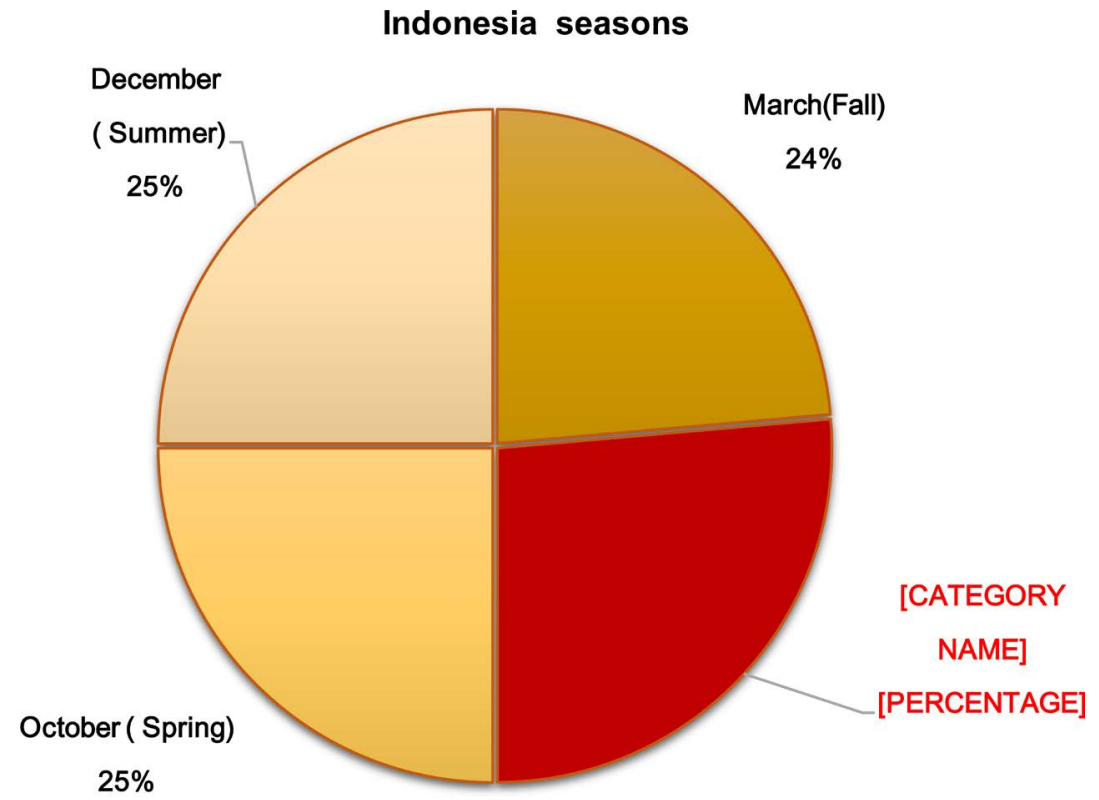

Figure 6. The Indonesia area presenting small seasonal variation differences.

\subsection{South America Region}

The deep depth earthquakes in South America usually do not have many events in a year. If you observe Table 9, there are inumerous gaps, with zero occurrences. It displayed a very small number of occasions as 1990 when almost all months presented zero events. However, another explanation it would be the events from South America are not recorded as in other regions around the globe. Tough, with fewer occurrences was possible to construct a solid table in the period we choose.

There are anomalies in Table 9 occurring mostly during the two years, in November and December of 2015, and the following year in January, October, and November. Statistically, the year 2015 will introduce instability in the period researched and cannot be considered in our study. The discrepancy in November could be associated with other sources besides seasonality. Figure 7 displays the South America monthly variation without the anomaly number, as the entire year of 2015 was taken out. The increases occur in March (Fall) and June (Winter).

Table 10 shows the seasons enhancements and the yearly percentage. The entire year presented for the period shows an increase of $40 \%$ in November (Spring) and Fall, and Winter shows a smaller evolution rate. This abnormal activity in November is due to the sudden incongruity in 2015 perhaps caused by a reason other than seasons.

Figure 8 shows the percentages of events by season, apparently during Fall and Winter the events increase in South America. During Spring, it is the lowest number of earthquakes in the region.

\subsection{Fiji and Vanuatu Region}

Table 11 illustrates the enhancement of earthquake events in this region 
showed, during the first seven months of the year, there is only $8 \%$ of activity and after July it increases to $9 \%$ completing the last five months; therefore, increasing of seasonality in the area will be between August to December. Those months perform $45 \%$ of all activity.

Table 9. The average number of events in South America over the last thirty years. The occurrences are one of the lowest from the five regions chosen. There is an anomaly in November 2015; the cause is unknown and was ignored. Observe entire columns with zero occurrence as September and November.

\begin{tabular}{|c|c|c|c|c|c|c|c|c|c|c|c|c|}
\hline Year & January & February & March & April & May & June & July & August & September & October & November & December \\
\hline 1987 & 1 & 2 & 0 & 2 & 1 & 1 & 0 & 2 & 1 & 1 & 4 & 0 \\
\hline 1988 & 1 & 0 & 0 & 0 & 0 & 1 & 0 & 0 & 0 & 0 & 0 & 1 \\
\hline 1989 & 0 & 1 & 0 & 0 & 2 & 0 & 0 & 0 & 0 & 0 & 0 & 0 \\
\hline 1990 & 0 & 1 & 1 & 0 & 0 & 0 & 0 & 0 & 0 & 3 & 1 & 1 \\
\hline 1991 & 1 & 2 & 0 & 0 & 0 & 4 & 1 & 0 & 0 & 0 & 0 & 0 \\
\hline 1992 & 0 & 0 & 0 & 0 & 2 & 0 & 0 & 0 & 0 & 0 & 0 & 0 \\
\hline 1993 & 0 & 2 & 0 & 0 & 1 & 1 & 1 & 0 & 0 & 0 & 0 & 0 \\
\hline 1994 & 1 & 0 & 0 & 1 & 0 & 2 & 0 & 0 & 0 & 0 & 3 & 1 \\
\hline 1995 & 1 & 0 & 1 & 0 & 2 & 0 & 0 & 0 & 0 & 0 & 3 & 0 \\
\hline 1996 & 1 & 0 & 0 & 1 & 1 & 0 & 0 & 1 & 1 & 0 & 0 & 1 \\
\hline 1997 & 0 & 1 & 4 & 1 & 2 & 1 & 1 & 0 & 0 & 0 & 1 & 1 \\
\hline 1998 & 1 & 0 & 1 & 2 & 1 & 0 & 1 & 0 & 1 & 1 & 1 & 1 \\
\hline 1999 & 0 & 1 & 1 & 0 & 0 & 1 & 1 & 0 & 1 & 0 & 0 & 1 \\
\hline 2000 & 0 & 1 & 0 & 3 & 0 & 1 & 0 & 2 & 0 & 0 & 0 & 0 \\
\hline 2001 & 0 & 0 & 2 & 1 & 1 & 0 & 0 & 1 & 0 & 0 & 0 & 0 \\
\hline 2002 & 0 & 0 & 0 & 1 & 3 & 1 & 0 & 1 & 0 & 1 & 1 & 0 \\
\hline 2003 & 0 & 2 & 2 & 1 & 0 & 1 & 1 & 3 & 0 & 0 & 0 & 0 \\
\hline 2004 & 1 & 1 & 0 & 2 & 0 & 0 & 0 & 0 & 0 & 0 & 3 & 1 \\
\hline 2005 & 2 & 0 & 2 & 1 & 1 & 0 & 1 & 0 & 1 & 1 & 1 & 0 \\
\hline 2006 & 0 & 0 & 3 & 1 & 1 & 0 & 1 & 1 & 2 & 0 & 2 & 0 \\
\hline 2007 & 0 & 2 & 1 & 0 & 1 & 1 & 0 & 1 & 0 & 0 & 1 & 0 \\
\hline 2008 & 1 & 1 & 0 & 2 & 1 & 0 & 1 & 0 & 2 & 1 & 1 & 1 \\
\hline 2009 & 1 & 0 & 0 & 1 & 0 & 1 & 1 & 0 & 0 & 0 & 2 & 0 \\
\hline 2010 & 2 & 0 & 0 & 1 & 1 & 0 & 1 & 1 & 0 & 0 & 2 & 0 \\
\hline 2011 & 0 & 2 & 0 & 3 & 1 & 1 & 1 & 1 & 1 & 1 & 0 & 0 \\
\hline 2012 & 0 & 0 & 1 & 0 & 3 & 5 & 0 & 0 & 0 & 2 & 1 & 1 \\
\hline 2013 & 1 & 1 & 1 & 0 & 0 & 0 & 0 & 0 & 0 & 1 & 0 & 0 \\
\hline 2014 & 2 & 0 & 0 & 2 & 1 & 0 & 1 & 0 & 0 & 1 & 4 & 0 \\
\hline 2015 & 1 & 0 & 1 & 1 & 1 & 0 & 0 & 1 & 2 & 1 & 20 & 3 \\
\hline 2016 & 3 & 0 & 1 & 1 & 1 & 1 & 1 & 0 & 1 & 3 & 3 & 1 \\
\hline 2017 & 0 & 2 & 0 & 0 & 0 & 0 & 1 & 0 & 0 & 0 & 0 & 1 \\
\hline
\end{tabular}




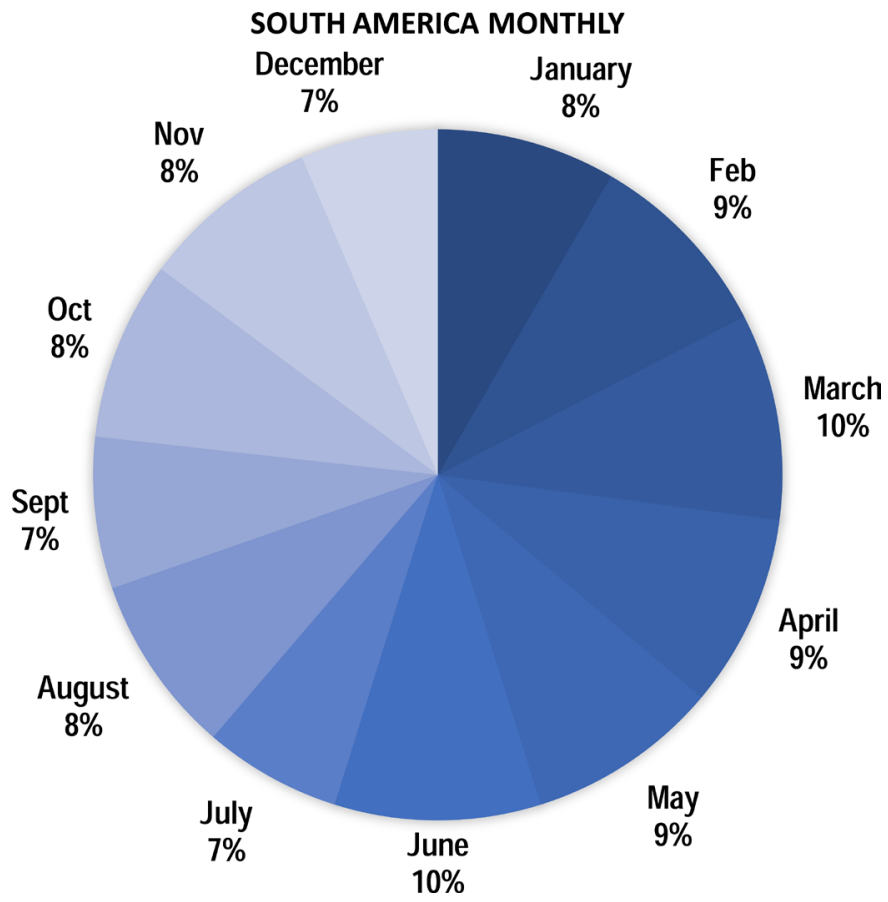

Figure 7. South America seasonality showing small increases during Fall (March) and Winter (June).

Table 10. Monthly enhancements and correspondent seasons.

\begin{tabular}{cc}
\hline Seasons & average \\
\hline February (Summer) & 1.4 \\
March (Fall) & 1.5 \\
June (Summer) & 1.5 \\
Oct/Nov. (Spring) & 1.3 \\
\hline
\end{tabular}

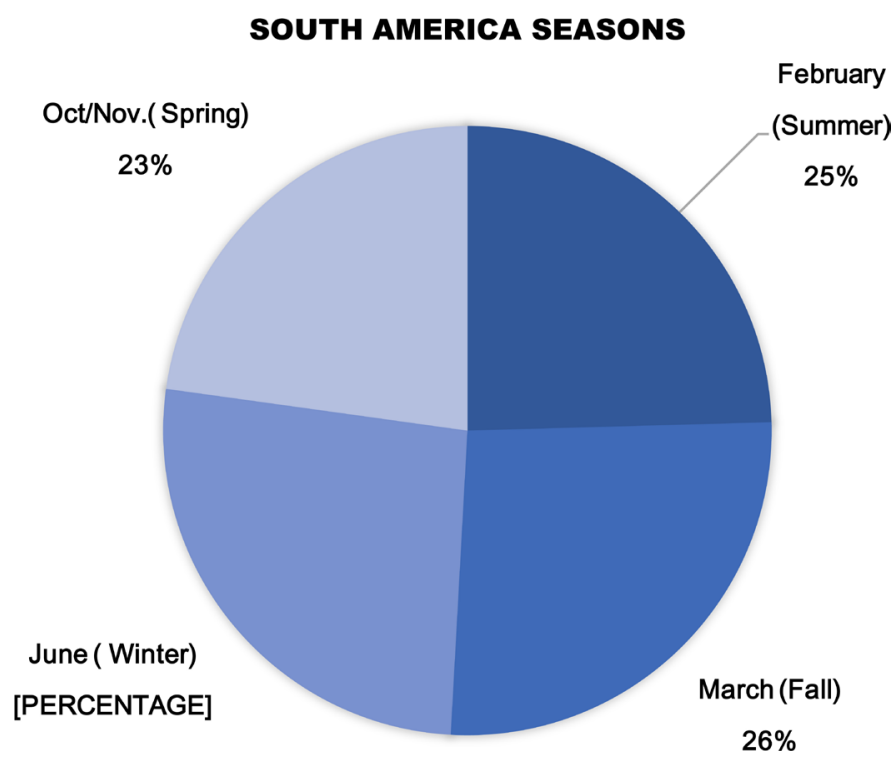

Figure 8. Season in South America does not show significant differences between each other. 
Table 11. The last region analyzed is Fiji, and the table is constructed in the same statistical manner as the previous tables. This location showed a continue number of earthquakes for all months, with small gaps as zero.

\begin{tabular}{|c|c|c|c|c|c|c|c|c|c|c|c|c|}
\hline Year & January & February & March & April & May & June & July & August & September & October & November & December \\
\hline 1987 & 0.5 & 0 & 0.5 & 0.5 & 0.5 & 0 & 0.5 & 0.5 & 0.5 & 0 & 0.5 & 0.5 \\
\hline 1988 & 0 & 1 & 0.5 & 0.5 & 0.5 & 0.5 & 0.5 & 0.5 & 0.5 & 0 & 0.5 & 0 \\
\hline 1989 & 0 & 0 & 0.5 & 0.5 & 0.5 & 0 & 0.5 & 0.5 & 0.5 & 1 & 0.5 & 0.5 \\
\hline 1990 & 0.5 & 0.5 & 0.5 & 0 & 0.5 & 0.5 & 1 & 0 & 0.5 & 1 & 0.5 & 0 \\
\hline 1991 & 1 & 0 & 0 & 0.5 & 0 & 0.5 & 0.5 & 0 & 0 & 0.5 & 0 & 1 \\
\hline 1992 & 0.5 & 0 & 0 & 0 & 1 & 0.5 & 0 & 1 & 0.5 & 0 & 0 & 0.5 \\
\hline 1993 & 0.5 & 0 & 0.5 & 1 & 1 & 0.5 & 0.5 & 0.5 & 0.5 & 0.5 & 0 & 0.5 \\
\hline 1994 & 0 & 0 & 1 & 1 & 0.5 & 0 & 0.5 & 1 & 0.5 & 0 & 0.5 & 0 \\
\hline 1995 & 0.5 & 0 & 1.0 & 1 & 1 & 1 & 1 & 1 & 1 & 1 & 1 & 0.5 \\
\hline 1996 & 1 & 1 & 1 & 1 & 1 & 1 & 1.5 & 1.5 & 1.5 & 1 & 1.5 & 1.5 \\
\hline 1997 & 2 & 1 & 2 & 1.5 & 1 & 1 & 1 & 1.5 & 1 & 1 & 1 & 1.5 \\
\hline 1998 & 1 & 2 & 1 & 1 & 1.5 & 1 & 1 & 1 & 1 & 1 & 1 & 1 \\
\hline 1999 & 1 & 1 & 1 & 1 & 1 & 1 & 1 & 1 & 0.5 & 0.5 & 1 & 0.5 \\
\hline 2000 & 1 & 1 & 1 & 1 & 1 & 1 & 1 & 1 & 1 & 1 & 1 & 1 \\
\hline 2001 & 0.5 & 1 & 1 & 1 & 1 & 1 & 1 & 1 & 1 & 1.5 & 1 & 1 \\
\hline 2002 & 1 & 1 & 1 & 1 & 1 & 1.5 & 1 & 2 & 1.5 & 1.5 & 1.5 & 1.5 \\
\hline 2003 & 1 & 1 & 1 & 1.5 & 1 & 1 & 1 & 1.5 & 1.5 & 1.5 & 1.5 & 1 \\
\hline 2004 & 1 & 2 & 1 & 1.5 & 1.5 & 2 & 1.5 & 1.5 & 1.5 & 1.5 & 2 & 2 \\
\hline 2005 & 1 & 1 & 1.5 & 1 & 1 & 1.5 & 1.5 & 1 & 1 & 1.5 & 1.5 & 1.5 \\
\hline 2006 & 2 & 2 & 1.5 & 1.5 & 1.5 & 1.5 & 1.5 & 1.5 & 1.5 & 1.5 & 2 & 1.5 \\
\hline 2007 & 2 & 1 & 1 & 1 & 1.5 & 1 & 1.5 & 1 & 1 & 1 & 1 & 1 \\
\hline 2008 & 2 & 1 & 1 & 1 & 1.5 & 1.5 & 2 & 1.5 & 2 & 1 & 2.5 & 2 \\
\hline 2009 & 0.5 & 0 & 0.5 & 0.5 & 0.5 & 0 & 0 & 0 & 0 & 0 & 0 & 0.5 \\
\hline 2010 & 0.5 & 0 & 0.5 & 0 & 0 & 0 & 0 & 0 & 0 & 0.5 & 0 & 0.5 \\
\hline 2011 & 0 & 0 & 0.5 & 0.5 & 0.5 & 0 & 1 & 1 & 0 & 0 & 0 & 0 \\
\hline 2012 & 0.5 & 1 & 0.5 & 0.5 & 0.5 & 0.5 & 0.5 & 0.5 & 0 & 0.5 & 0.5 & 0 \\
\hline 2013 & 0.5 & 0 & 1 & 0.5 & 0.5 & 0.5 & 0.5 & 0.5 & 1 & 1.5 & 2 & 1.5 \\
\hline 2014 & 2 & 2 & 2 & 2 & 2.5 & 2 & 2 & 2 & 2 & 2 & 2.5 & 2.5 \\
\hline 2015 & 2 & 2 & 2 & 2 & 2 & 2.5 & 1.5 & 1.5 & 1.5 & 2 & 1.5 & 1.5 \\
\hline 2016 & 2 & 2 & 1 & 2 & 2 & 2 & 1.5 & 2.5 & 3 & 2.5 & 2 & 1.5 \\
\hline 2017 & 2 & 2 & 1 & 2 & 2 & 2.5 & 2 & 2 & 2 & 2 & 1.5 & 1 \\
\hline
\end{tabular}

It is possible to indicate that the activity on the area has a slight increase after August, which is during Winter. Table 12 shows the Fiji seasonality during the year.

Figure 9 was constructed from Table 12 all seasons, but Summer had two 
Table 12. This is showing a perfect balance between the months and seasons; the initial conditions are the same as $M \geq 2.5$, depths $\geq 500 \mathrm{~km}$, the area is around Fiji and Vanuatu. There are seasons when the same enhancement involving two months as Fall, Winter, and Spring.

\begin{tabular}{cc}
\hline January (Summer) & 1 \\
April/May (Fall) & 1 \\
July/August (Winter) & 1 \\
October/November (Spring) & 1 \\
\hline
\end{tabular}

\section{FIJI SEASON}

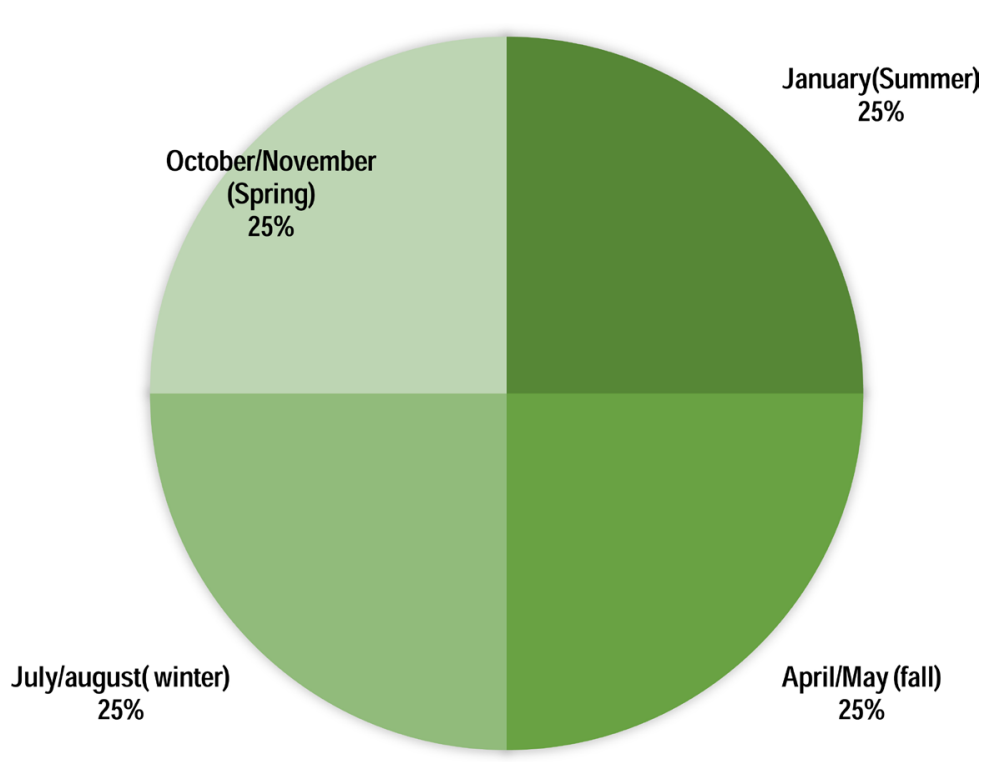

Figure 9. Fiji did not present seasonality as the other areas.

months with the same number of average earthquakes. The seasons did not affect enhancements or decreases during the entire year. Although some variances could be found when we considered earthquakes above magnitude M6 this present search, showed no distinctions among the seasons.

The result is comparable with other areas, such as South America; however, in South America, the number of occurrences is the lowest at the Southern Hemisphere and a few months during several years had a lack of records in the area, such as for April (Fall), August (Winter), and September (Spring).

Yet, it seems the east side of Circum Pacific had unusual activity. In the Northern Hemisphere there were no deep-depth occurrences, in the Southern Hemisphere it happens in traplate as it happens in South America, and, further, around Fiji and Vanuatu. It seems most of the activity is in the West Pacific, in both hemispheres. Seasonality appears to be in the cases studied in this paper, restricted to the western side of the Pacific, at subduction zones.

\section{Discussion of Results}

The results concluded that the areas examined at the Northern Hemisphere had 
enhancements of events during Spring and Summer. For example, North Pacific had increases most at the end of Spring and the middle/end of Summer. The total of earthquakes in those regions during Spring and Summer were $60 \%$ of total activity for the entire year.

Philippines behavior has 57\% of events during the Spring and Summer and the months with higher rates are May (Spring) and July (Summer).

Now, moving to the Southern Hemisphere, Indonesia had enhancements on the earthquakes during all six months, but most during Fall (March and May) and Spring (September and October) which give great variations in these results.

The analysis of the two other locations did not display the same variations during the year. One of the most significant problems working on the data from South America is the lack of recorded events in a month over several years. Our activity map had openings that perhaps did not correspond to reality. Nevertheless, earthquakes in South America do not happen in the oceans like they do in the other zones studied. It shows a system that is different from the other locations in the Northern or Southern Hemispheres. South America had an anomaly in 2015, when the earthquakes occurrences reached twenty times higher than normal. Although it would relate to the seasons, it was decided to ignore the year in our calculations. If we do, it becomes inexact to connect the earthquakes with a possible seasonality in the area. It is important to mention two months when the events are around 10\%: March (Fall) and June (Winter) which is an indication that other factors may apply, but seasons are essential in this area.

The last area considered was Fiji and Vanuatu which presented an exciting result as to the first part of the year. In the months of January through July (included) there is a perfect distribution of tremors around $8 \%$ of the total for each month (7\% for February). During the last part of the year, August through December, it increases to $9 \%$ by month, or $45 \%$ of the total earthquakes. Despite the encouraging results to this location in our recent paper using significant events of magnitude M6 or above, when we found Summer and Fall were 34\% of variations in the area, this study found nothing when all the magnitudes of $M \geq$ 2.5 considered. However, the small increase in the last five months, during the entire thirty-year period, would deserve some attention.

Finally, the total number of events indicated that the Northern Hemisphere at the West side of the Pacific may demand some seasonal variation. On the other hand, there are no ultra-deep earthquakes (UDQ) on the Northeast side of the Pacific; these don't begin to happen until lower latitudes, a little above the equator in South America. The Southeast Pacific side does not show any outstanding seasons like the Northwest, or Southwest Pacific; however, the Southwest Pacific is also a little closer to the equator than the areas considered on the east side.

Consequently, UDQ seasonality did not look to be ubiquitous; instead, it applies more to the higher latitudes or most locations nearest to the continents.

Now, compare the three Southern regions which did not presented much seasonality, Figure 5, Figure 7, Figure 10. Figure 5 is Indonesia monthly variations, 


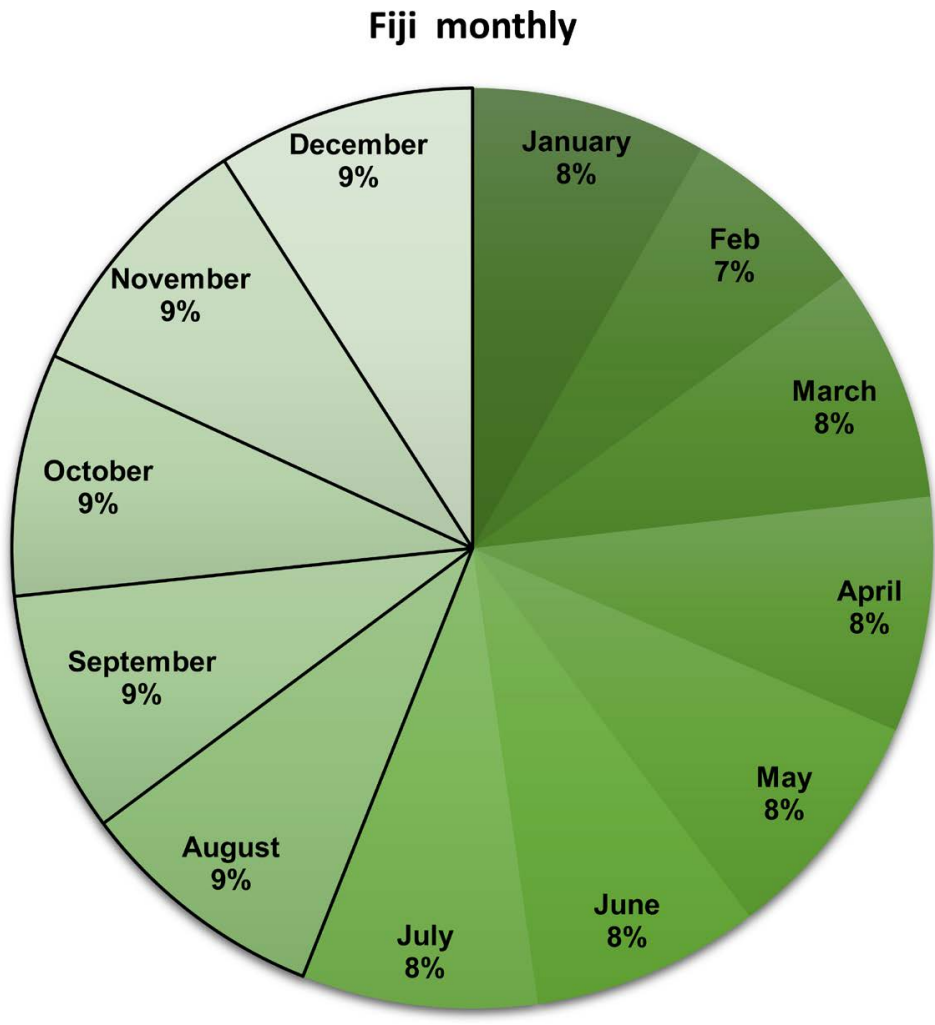

Figure 10. This area Fiji, Vanuatu presented seven months with $8 \%$ of variations and the last five months with $9 \%$ increases.

March, May, July, September, October and December each of them, present 11\% of the total of earthquakes. South America (Figure 7) has enhancements in March, June of $10 \%$. Fiji, the Figure 10 showed seven months January - July with $8 \%$ each of the total number of quakes (exception February) with the last of five months with $9 \%$ of activity. The three areas at the Southern Hemisphere displayed not seasonal variations instead it is clear periodicity of quakes in such subduction zones. Overall, the periodicity of tremors at the Southern Hemisphere is higher than any correlation with seasons.

\section{Conclusions}

The final conclusions for this UDQ worldwide study showed, for the initial conditions with magnitudes of $M \geq 2.5$, there is evidence for seasonality at the Northwest Pacific, less evidence for the Southwest Pacific, and none for the Southeast Pacific. Such results cannot be considered final or generalized for earthquake seasonality around the globe. At this point, there are many restrictions in our studies.

It is essential to make other parameters more flexible in our calculations to enable a better statistical study. For example, considering different depths will make the system more full for possible comparisons. The only problem will always be those points around the equator where one part of the events occurs in the Northern Hemisphere and the other in the Southern Hemisphere; it makes 
complicate to precise seasons on the locations searched. Southern Hemisphere showed periodicity of events during the period analyzed to any magnitude searched.

\section{Conflicts of Interest}

The authors declare no conflicts of interest regarding the publication of this paper.

\section{References}

[1] Hagen, M. and Azevedo, A. (2018) Deep and Ultra-Deep Earthquakes Worldwide, Possible Anomalies in South America. Natural Science, 10, 199-213. https://doi.org/10.4236/ns.2018.106022

[2] Hagen, M. and Azevedo, A. (2018) Possible Connections between Seasons and Ultra-Deep Earthquakes Worldwide. Natural Science, 10, 288-302. https://doi.org/10.4236/ns.2018.107029

[3] Zhonghwen, Z. and Shearer, P. (2015) Possible Seasonality in Large Deep-Focus Earthquakes. Geophysical Research Letters, 42, 1-8.

[4] Hagen, M. and Azevedo, A. (2018) Seasonality and Tectonic Influences on Subduction Zones for Ultra-Deep Earthquakes. Open Journal of Earthquake Research, 7, 269-284. https://doi.org/10.4236/ojer.2018.74014

[5] https://earthquake.usgs.gov/earthquakes/search/

[6] https://www.emsc-csem.org/Earthquake/?filter=yes 